\title{
Mathematical Analysis of Inclusion Removal from Liquid Steel by Gas Bubbling in a Casting Tundish
}

\author{
H. Arcos-Gutierrez, J. de J. Barreto, S. Garcia-Hernandez, \\ and A. Ramos-Banderas \\ Instituto Tecnologico de Morelia, Metallurgy Graduate Center, Av. Tecnologico No. 1500, 58120-Morelia, \\ Michoacan, Mexico \\ Correspondence should be addressed to S. Garcia-Hernandez, iq_sagahz@hotmail.com
}

Received 5 February 2012; Revised 16 April 2012; Accepted 27 April 2012

Academic Editor: M. F. El-Amin

Copyright (C) 2012 H. Arcos-Gutierrez et al. This is an open access article distributed under the Creative Commons Attribution License, which permits unrestricted use, distribution, and reproduction in any medium, provided the original work is properly cited.

\begin{abstract}
The mechanism of inclusion removal from liquid steel by gas bubbling and bubble attachment in the tundish is complex due to the great number of variables involved, and it is even more difficult to study because of the turbulent flow conditions. The main objective of this work is to analyze and improve the understanding of the alumina inclusion removal rate by bubble attachment and by gas bubbling fluid dynamics effects. The results show that the inclusion collection probability mainly depends on the attachment mechanism by collision. This parameter was determined by calculating the induction time, which is shorter when the rupture time and the formation time of a stable three phases contact (particle/liquid/gas) are ignored than when it is fully considered, affecting the attachment probability. In addition, to achieve acceptable inclusion removal, a smaller bubble diameter is required, such as $1 \mathrm{~mm}$. This consideration is almost impossible to achieve during tundish operation; a more realistic bubble diameter around $10 \mathrm{~mm}$ is employed, resulting in a very inefficient inclusion removal process by bubble attachment. Nevertheless, in a real casting tundish the inclusion removal rate employing argon bubbling is efficient; is mainly due to the fluid flow pattern changes rather than bubble attachment. Consequently, it is imperative to consider the summation of both removal mechanisms to compute a better approximation of this important operation.
\end{abstract}

\section{Introduction}

Due to the stringent control on the cleanliness of the steel, many steel casting shops around the world have studied extensively the tundish systems employed, not only to maximize the benefits of increasing the residence time by flow control and reduce contamination, but also to have better and faster assimilation of the non metallic inclusions by the slag. The most recent research reported in the open literature on the subject of inclusion removal in tundish can 
be grouped in three main subjects: the effect of the fluidynamics on the inclusion trajectories $[1-5]$, the mechanisms of inclusions assimilation by the slag $[6,7]$, and the mechanisms of inclusion removal by bubble flotation [4, 8-28].

Argon bubbling is a very attractive technology used as a flow control and inclusion removal, it strongly affects the fluid flow patterns in the tundish by reducing the dead flow zones and by increasing the plug flow together with the mean residence time [22-24, 27]. In addition, it has been found by industrial trial that the implementation of this operation improves the inclusion removal rate by decreasing the final range of inclusion size, and the inclusion ratio in the final product $[25,28]$. Furthermore, there are some works focusing on the main variables that control the particle-bubble flotation mechanisms [16-19]. Even with all this research, there is a gap in the knowledge of the inclusion-bubble interaction in the tundish and its effect on the removal rate. A few efforts have been done to study this subject, such as the work done by Rogler et al. [20], where the porous zone width effect on the inclusion removal in the tundish was studied. However, in this work many assumptions were taken, for instance considering constant the collection probability. Another important effort was developed by Zhang and Taniguchi [4] where the silica inclusion removal by bubble flotation in the ladle was determined by using the oscillation model.

Equally important is to consider the detrimental effect of the submerged entry nozzle clogging by alumina inclusions in the tundish and the limited understanding on the subject. Therefore, the objective of this work is to analyze mathematically and analytically the alumina inclusion removal rate before they get to the submerge entry nozzle by bubble attachment mechanism, considering attachment by oscillation or sliding models and the collection probability as a function of complete induction time, and by the bubbling fluidynamic effects.

\section{Model Development}

A fluidynamics mathematical model was developed based on a previous published work by the authors [9] and an analytical model was developed to understand the attachment mechanism for inclusion removal in the tundish. The fundamental equations and mechanisms are described as follows.

\subsection{Mechanisms for Particle-Bubble Interaction}

The mechanism for inclusion attachment to the bubble can take place by collision (if $t_{c}>t_{\mathrm{fr}}$ ) or by sliding (if $t_{s}>t_{\mathrm{fr}}$ ). Both are considered in this work. This mechanism has been widely studied and it is composed of six steps [14]:

(1) inclusion approximation to the bubble;

(2) liquid film formation between inclusion and bubble;

(3) oscillation or sliding of the inclusion on the bubble surface;

(4) drainage and rupture of the film to achieve the three phase contact (TPC);

(5) stabilization of the system particle-bubble against external stresses;

(6) flotation of the stable system inclusion-bubble.

This mechanism is influenced by many parameters, where the system is very sensitive. Those parameters are as follows. 
Collision time $\left(t_{c}\right)$ is calculated by Evans' model [13],

$$
t_{c}=\left(\frac{\pi^{2} \rho_{p}}{12 \sigma_{L}}\right)^{1 / 2} d_{p}^{3 / 2}
$$

Drainage time $\left(t_{\mathrm{fr}}\right)$ is determined by Schulze's model [19],

$$
t_{\mathrm{fr}}=\frac{3}{64}\left(\frac{\pi}{180}\right)^{2} \frac{b_{\alpha}^{2}\left(32 u_{R} t_{c}\right)^{2 m_{\alpha}} \mu_{L} d_{p}^{3}}{\sigma_{L} k h_{\text {crit }}^{2}} .
$$

Critical film thickness $\left(h_{\text {crit }}\right)$ is calculated by Sharma and Ruckenstein Hole Formation model [13]. This model considers irregular inclusion shapes,

$$
h_{\text {crit }}=-2 \sigma_{l}+\frac{\left(4 \sigma_{l}^{2}+2 \rho_{L} g \sigma_{l}(1-\cos \theta) r^{2}\right)^{1 / 2}}{\rho_{L} g r} .
$$

Sliding time $\left(t_{s}\right)$ is calculated by Nguyen's model [17, 18],

$$
t_{s}=\frac{d_{P}+d_{B}}{2 u_{B}\left(1-B^{2}\right) A} \ln \left\{\frac{\tan \left(\theta_{c} / 2\right)}{\tan \left(\theta_{0} / 2\right)}\left[\frac{\operatorname{cosec} \theta_{c}+B \cot \theta_{c}}{\operatorname{cosec} \theta_{0}+B \cot \theta_{0}}\right]^{B}\right\}
$$

Bubble diameter $\left(d_{b}\right)$ is calculated as a function of Orifice Reynolds number,

$$
\begin{gathered}
N_{\mathrm{Re}, O}=\frac{u d_{0} \rho_{g}}{\mu_{L}}=\frac{4 Q_{g} \rho_{g}}{\pi d_{0} \mu_{L}} \\
N_{\mathrm{Re}, 0}<500 \longrightarrow d_{B}=\left[\frac{6 d_{0} \sigma_{L}}{g\left(\rho_{L}-\rho_{G}\right)}\right]^{1 / 3} \text { and to } N_{\mathrm{Re}, 0}>5000 \longrightarrow d_{B}=\frac{1.3 Q_{g}^{6 / 5}}{g^{3 / 5}} .
\end{gathered}
$$

Bubble velocity $\left(u_{b}\right)$, Davies and Taylor's model is used for bubbles of spherical cap shape with a bigger diameter than $6 \mathrm{~mm}$ [22], and the Stokes model for the bubble diameter smaller than $1 \mathrm{~mm}$,

$$
u_{B}=1.02\left(\frac{g d_{B}}{2}\right)^{1 / 2}, \quad u_{B}=\frac{d_{B}^{2}}{18 \mu_{L}} g\left(\rho_{L}-\rho_{G}\right)
$$

Induction Time $\left(t_{i}\right)$ is determined by the complete Nguyen's model [18],

$$
t_{i}=\frac{d_{P}+d_{B}}{2 u_{B}\left(1-B^{2}\right) A} \ln \left\{\frac{1 / \sqrt{P_{\mathrm{at}}}+\sqrt{1 / P_{\mathrm{at}}+D^{2}-1}}{\left(1 / \sqrt{P_{\mathrm{at}}}+B \sqrt{1 / P_{\mathrm{at}}+D^{2}-1}\right)^{B}} \times \frac{(1+B D)^{B}}{1+D}\right\}
$$

The induction time is a relatively new parameter that has not been fully studied. 


\subsection{Inclusion Collection Probability}

The overall probability (2.8) is the product of the attachment probability (Equation (2.9), Yoon's model [14]), the collision probability (Equation (2.10), Nguyen's semianalytic model $[17,18])$, and one minus the detachment probability, which is considered equal to zero,

$$
\begin{gathered}
P=P_{C} \cdot P_{\mathrm{at}}\left(1-P_{\mathrm{det}}\right) \\
P_{\mathrm{at}}=\operatorname{sen}^{2}\left[2 \arctan \exp \left(-\frac{2 t_{\mathrm{fr}}}{d_{b}+d_{p}} X\right)\right] \\
X=\left[\left\{\left[1-\frac{3}{4 x_{E}}-\frac{1}{4 x_{E}^{3}}+\frac{\operatorname{Re}_{B}^{0.72}}{15}\left(-\frac{2}{x_{E}^{4}}+\frac{1}{x_{E}^{3}}+\frac{1}{x_{E}}\right)\right] u_{b}-u_{p}\right\}\right], \quad x_{E}=1+k_{2}, k_{2}=\frac{d_{p}}{d_{b}} \\
P_{C}=\frac{2 u_{B} D}{9\left(u_{B}+u_{P}\right) Y}\left(\frac{d_{P}}{d_{B}}\right)^{2}\left[\sqrt{(X+C)^{2}+3 Y^{2}}+2(X+C)\right]^{2} .
\end{gathered}
$$

The model proposed by Rogler et al. is used [20] to study the alumina inclusion removal rate in the tundish. In this model the inclusion concentration is a function of the residence time and it is given by

$$
-\frac{d n}{d t}=N_{T}=k n, \quad \text { where } N_{T}=N_{C C} \cdot N_{B}=\frac{3 q_{G} P T_{F}}{2 d_{B} T_{0}} \cdot n=k \cdot n,
$$

where: $n=n_{0} e^{-k \tau}$.

The inclusion removal efficiency is expressed for

$$
\varepsilon=\left(1-e^{k \tau}\right) \cdot 100
$$

\subsection{Mathematical Model Considerations and Boundary Conditions}

The fluidynamic model consists-of the fundamental Navier-Stokes equations, together with the $k-\varepsilon$ turbulence model and the discrete phase model [9] embedded in the commercial CFD code FLUENT. The liquid steel flowing in the tundish is assumed to have Newtonian behavior, under isothermal and steady state conditions. Both turbulent and laminar flows coexist in the tundish; however, only laminar flow is present close to solid walls. Consequently, typical nonslipping conditions were applied to all solid surfaces. Wall functions were used at the nodes close to any wall. The gravity force was considered to act over the y-coordinate. No slag layer was considered, instead a plane surface was assumed where the velocity gradients, turbulent kinetic energy, and its dissipation rate are taken as zero.

To study the macroscopic flow effect, the simulated inclusions were assumed to have a spherical rigid shape with the physical properties of alumina. No interaction among the inclusions was considered; therefore, agglomeration and collision were not simulated. The only inclusion removal mechanism considered was Stoke's flotation. Inclusion trajectories 
were calculated using a Langrangian particle-tracking approach, which solves a transport equation for each inclusion as they travel through the previous calculated velocity field of liquid steel. This approach assumes that the interaction between steel and the inclusion is one-way coupled, that is, only the steel affects the trajectories of inclusions but these do not affect the steel flow. The boundary conditions for inclusion removal were as follows: any inclusion that reached the free surface was considered removed and the rest was considered as escaped.

\subsection{Analytical Model Description and Considerations}

The argon bubbles have a constant size, and they are uniformly distributed in the bubble region. The bubble-bubble and inclusion-inclusion interactions are ignored. The inclusioninclusion collision as well as the agglomeration is not considered, and the inclusion size does not affect the bubble trajectory. The removal mechanisms considered are bubble flotation and buoyancy forces.

For the calculation of the inclusion removal rate by bubble attachment, five main programs were developed, for those the dimensionless constants $(A, B, C, D, X, Y$ all these constants were calculated with the equations proposed by Nguyen et al. $[17,18])$ were calculated as a function of the $\operatorname{Re}_{b}$. Program I: calculate $d_{b}, u_{b}, t_{i}, P_{a}, P_{c}, E_{\mathrm{ri}}, t_{c}, t_{\mathrm{fr}}, h_{\text {crit }}$ using small increments of the gas flow rate and the diameter of the pore in the porous plug. Program II: calculate $u_{p}, P_{c}, P_{a}, E_{\mathrm{ri}}, t_{c}, t_{i}, t_{\mathrm{fr}}, h_{\text {cri }}$ using different width of the bubble region, but considering constant the resident time of the steel, the bubble diameter, the gas flow rate, and the diameter of the pore in the porous region. Program III: calculate $P_{c}, P_{a}, t_{c}, t_{\mathrm{fr}}, h_{\text {crit }}$ using constant the inclusion diameter and the bubble diameter. Program IV: calculate $d_{b}, u_{b}$, $P_{a}, P_{c}, E_{\mathrm{ri}}, t_{c}, t_{\mathrm{fr}}, h_{\text {crit }}$ but employing constant the gas flow rate and the diameter of the pore in the porous plug. Program V: calculate $P, P_{a}, P_{c}, t_{s}, t_{c}, t_{\text {fr }}, t_{i}, h_{\text {crit }}$ for different bubble and inclusion diameters. This has been summarized in Table 1 .

\section{Results and Discussion}

\subsection{Analytical Analysis}

The first variable calculated was the Critical Film Thickness $\left(h_{\mathrm{cr}}\right)$ for alumina inclusions, this variable was predicted using the hole formation and oscillation models, and the Schulze and Birzer empirical relationship. The results are shown in Figure $1(\mathrm{a})$, where $h_{\mathrm{cr}}$ for this inclusion type has values between $0.015-452 \mathrm{~nm}$. Consequently, the dominant forces for the film draining and rupture are the Van der Waals forces. It was also observed that $h_{\text {cr }}$ value is bigger when it is calculated using the hole formation model indicating that the liquid film rupture takes place easier by the formation of a hole. Since this work is focused on inclusion sizes ranging between 1-40 microns, it can be observed that the predicted values for $h_{\mathrm{cr}}$ are in the zone of the experimental results in water systems. Furthermore, Figure 1(b) shows the $h_{\mathrm{cr}}$ results for silica inclusions reported by Zhang and Taniguchi [4], who established that $h_{\mathrm{cr}}$ value is 3 to 5 times higher for the hole formation model than the values obtained by oscillation model, concluding that the film rupture is easier by the formation of a hole. These authors suggested that for alumina inclusions the film drainage and rupture may occur by the formation of a hole, which is corroborated by the present results and it was concluded 


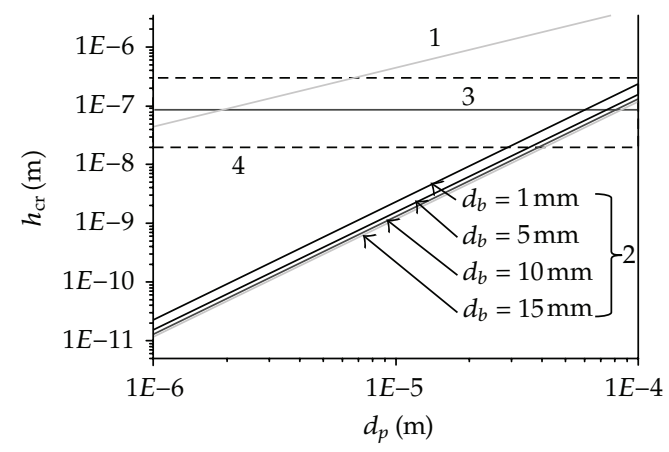

(a)

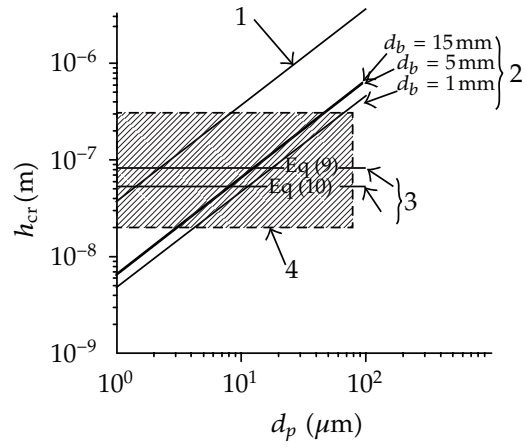

(b)

Figure 1: The critical film thickness $\left(h_{\mathrm{cr}}\right)$ calculated as a function of the inclusion diameter $\left(d_{p}\right),(\mathrm{a})$ alumina inclusion and (b) silica inclusion [13].

Table 1: Variables, parameters, and equations for each program developed.

\begin{tabular}{lcccc}
\hline Program & Variables calculated & $\begin{array}{c}\text { Parameter } \\
\text { modified }\end{array}$ & $\begin{array}{c}\text { Equation } \\
\text { numbers } \\
\text { employed }\end{array}$ & $\begin{array}{c}\text { Dimensionless } \\
\text { constants }\end{array}$ \\
\hline I & $d_{b}, u_{b}, P_{a}, P_{c}, E_{\mathrm{ri}}, t_{i}, t_{c}, t_{\mathrm{fr}}, h_{\mathrm{crit}}$ & $d_{p}, n_{0}, \tau, d_{0}, Q_{g}$ & $\begin{array}{c}1,2,3,5,6,7,9, \\
10,11\end{array}$ & $A, B, C, D, X, Y$ \\
II & $u_{p}, P_{c}, P_{a}, E_{\mathrm{ri}}, t_{c}, t_{\mathrm{fr}}, t_{i}, h_{\mathrm{cri}}$ & $d_{p}, n_{0}, \tau, d_{0}, Q_{g}, d_{b}$ & $\begin{array}{c}1,2,3,5,7,9,10, \\
11\end{array}$ & $A, B, C, D, X, Y$ \\
III & $P_{c}, P_{a}, t_{c}, t_{\mathrm{fr}}, h_{\mathrm{crit}}$ & $d_{p}, d_{b}$ & $1,2,3,10,11$ & $C, D, X, Y$ \\
IV & $d_{b}, u_{b}, P_{a}, P_{c}, E_{\mathrm{ri}}, t_{c}, t_{\mathrm{fr}}, h_{\mathrm{crit}}$ & $d_{p}, n_{0}, d_{0}, Q_{g}$ & $1,2,3,6,7,9,10$, & $A, B, C, D, X, Y$ \\
V & $P, P_{a}, P_{c}, t_{s}, t_{c}, t_{\mathrm{fr}}, t_{i}, h_{\mathrm{crit}}$ & $d_{p}, d_{b}$ & $1,2,3,4,5,6,7,9$, & $A, B, C, D, X, Y$ \\
\hline
\end{tabular}

that $h_{\mathrm{cr}}$ is dependent of the inclusion type, and the film rupture will take place by the hole formation mechanism, which will be the model to be considered further on.

It is well known that the inclusion attachment mechanisms to a bubble can be by collision or by sliding. For such reason, it is required to know the collision time $\left(t_{c}\right)$, the sliding time $\left(t_{s}\right)$, and the induction time $\left(t_{i}\right)$, since the controlling attachment mechanism is determined through these three variables. The induction time is the time required to achieve the drainage and rupture of the film, in order to reach a stable three phase contact (TPC). In previous research works, some of the considerations were taken to predict the induction time results in smaller values, for instance, Wang et al. [14] calculated $t_{i}=t_{\mathrm{fc}}$ without considering TPC rupture time and the time for the formation of the stable TPC; however, the authors advice that this assumption is not exact; this hypothesis was also considered by Rogler et al. [20]. Nevertheless, due to its importance, in the present work it has been fully calculated using Nguyen's model (2.7). The numerical values of these three time variables calculated for alumina inclusions are shown in Figure 2(a). Where it should be taken into account that if $t_{c}>t_{i}$, the inclusion attachment is by collision if $t_{c}<t_{i}$, the inclusion does not attach if $t_{s}>t_{i}$, the inclusion attachment is by sliding and if $t_{s}<t_{i}$ the inclusion slide; but it does not attach. Considering this as a reference, the results show that in general $t_{i}>t_{c}$ for the studied bubble diameters; consequently, the alumina inclusion attachment occurs by sliding 


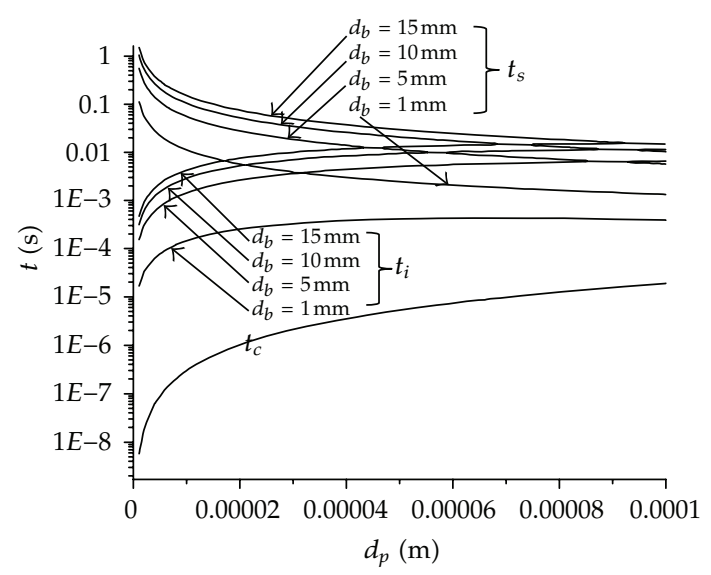

(a)

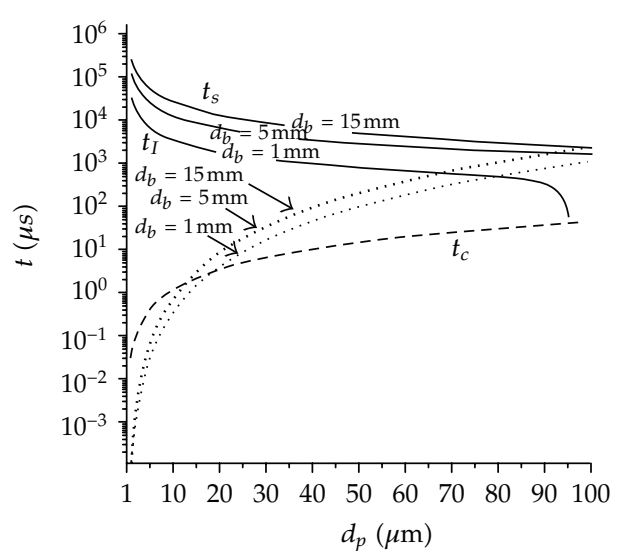

(b)

Figure 2: Relationship of the Inclusion Diameter to the collision, sliding and induction times. (a) $t_{i}$ calculated using the Nguyen's equation and (b) $t_{i}$ reported by Zhang and Taniguchi [13].

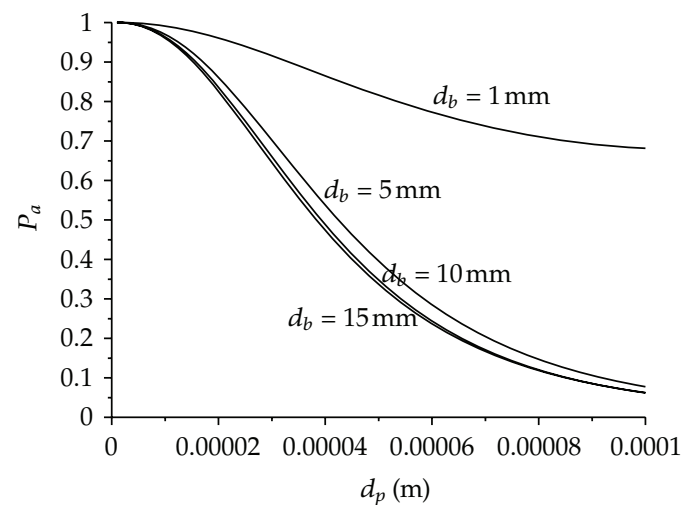

(a)

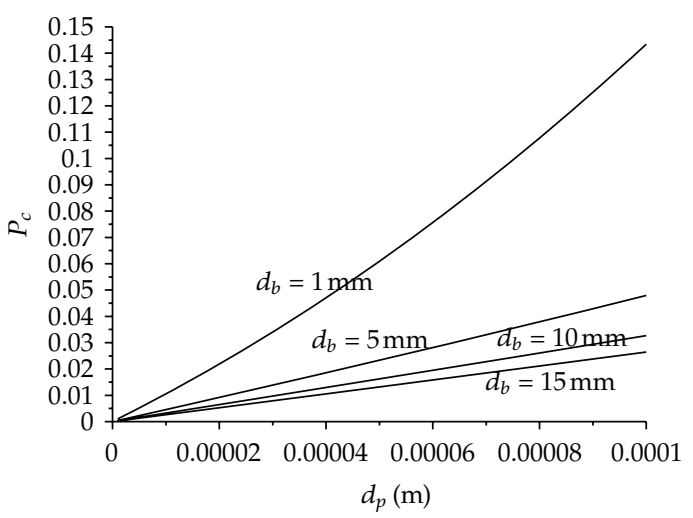

(b)

Figure 3: (a) Attachment Probability and (b) Collision Probability.

or bouncing back, but it will not take place by collision. About the variable $t_{s}$ when the bubble size is $1 \mathrm{~mm} t_{s}>t_{i}$, meaning that the inclusion attaches by sliding, and when the bubbles size is $5 \mathrm{~mm} t_{s}>t_{i}$ but only for particles diameters up to $83 \mu \mathrm{m}$. Figure 2(a) also shows the limit for inclusion diameter that may attach to a bubble, which is identified by the intersecting point of $t_{s}$ and $t_{i}$. The present results show bigger $t_{i}$ values and therefore smaller limits compared to those obtained previously by Zhang and Taniguchi [13]. Therefore, it is essential to select adequately the model used for compute $t_{i}$.

To predict the inclusion removal rate in the tundish, it is required the collection probability which depends on the attachment and collision probabilities; for this reason, these probabilities are first analyzed. Figure 3(a) shows the calculated $P_{\text {att }}$ values as a function of the bubble and particle diameters, where it can be seen that for $d_{p}<10$ microns the values obtained are close to unity, independently of the $d_{b}$. This indicates that any inclusion that impacts a bubble will be removed. On the other hand, for $d_{p}>10$ microns the $P_{\text {att }}$ becomes a function of $d_{b}$, for example for $d_{b}=1 \mathrm{~mm}$ the $P_{\text {att }}$ is high; nevertheless, for $d_{b}=5 \mathrm{~mm}$ 


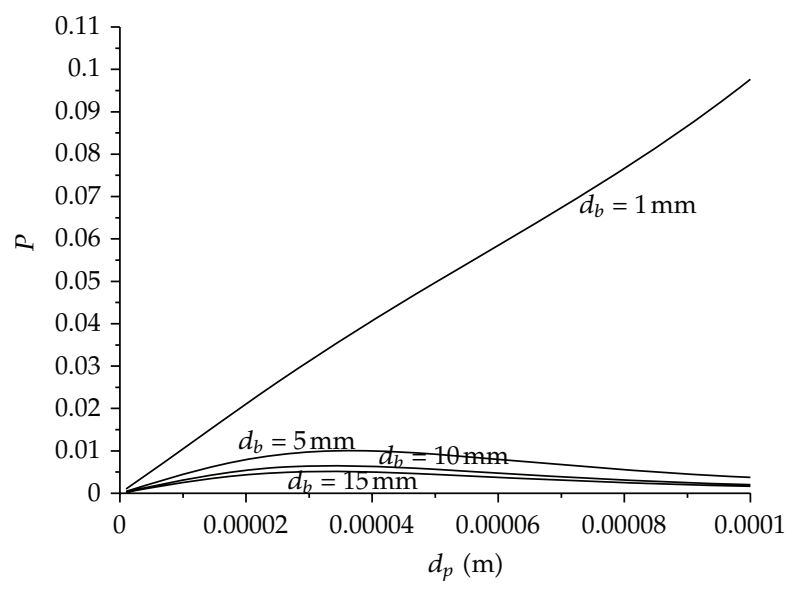

Figure 4: Collection Probability.

the $P_{\text {att }}$ decreases exponentially. Moreover, for bigger bubble diameters such as 10 or $15 \mathrm{~mm}$, the $P_{\text {att }}$ shows values and a declined profile similar to $d_{b}=5 \mathrm{~mm}$. These results are in accordance to previous works published in the open literature $[13,14,20]$, which means that the present model predicts correctly the $P_{\text {att }}$ and allows to conclude that it is necessary to have $d_{b}<5 \mathrm{~mm}$ to remove efficiently small alumina inclusions in the range of 1-40 microns.

Figure 3(b) shows that, in general, the collision probability is very low independently of the bubble and inclusion sizes. It is important to state that if an inclusion collides with a bubble, the removal probability will be high. In order to improve the collision probability considering the above inclusion size range, it is required that bubble diameters be smaller than $1 \mathrm{~mm}$. However, in the liquid steel flowing inside the tundish it is extremely difficult to get argon bubble diameters as small as $1 \mathrm{~mm}$; therefore, the $P_{c}$ will be very low and consequently the collection probability will be even smaller, this can be observed in Figure 4 . Taken into consideration the calculated information, the inclusion removal rate in the tundish by bubble attachment may not be as efficient as can be expected and it is perhaps more dependent on other variables. According to this hypothesis, it is required to calculate the inclusion removal rate $\left(R_{E}\right)$ of a typical two-strand tundish. To determin this variable, it was necessary to define some parameters, such as the width of the porous media considering both sides $\left(L_{B}\right)$, the tundish mean residence time $\left(T_{R}\right)$ and the mean residence time inside the bubble zone $\left(T_{R B}\right)$; the last two are directly related with the steel level which was set as constant implicating that $T_{R}$ is constant, and $T_{R B}$ depends only on the $L_{B}$ variable. With these conditions, $R_{E}$ was calculated using the Rogler and Heaslip model [20] and the results are shown in Figure 5(a). In this figure, the requirement of small bubble diameters to get an efficient inclusion removal is evident once more. Through these results the declared hypothesis in Figure 4 is confirmed, since $R_{E}$ values are smaller than $30 \%$ for inclusion in the interest range with $10 \mathrm{~mm}$ argon bubble diameter.

In spite of the small values mentioned above, it is necessary to find out the controlling variable on $R_{E}$. In order to achieve this goal, some variations were considered and their effects were analyzed against the $R_{E}$ value of $21 \%$ for $d_{p}=30$ microns and $b_{d}=10 \mathrm{~mm}$. First, the $T_{R}$ was decreased from 600 to 400 seconds, Figure 5(b). This change turned out in a $33 \%$ decrease of $T_{R B}$, consequently a $34 \%$ decrease of $R_{E}$ reference value was observed. Second, reducing by half $L_{B}$ and keeping $T_{R}$ constant, Figure $5(\mathrm{c})$, the $T_{R B}$ value was diminished to 


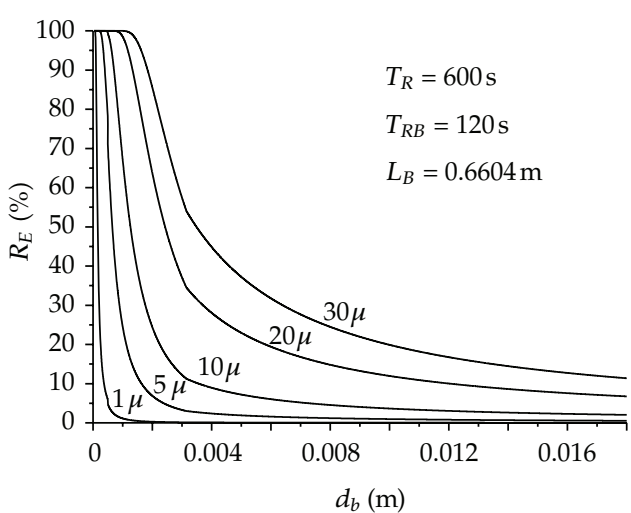

(a)

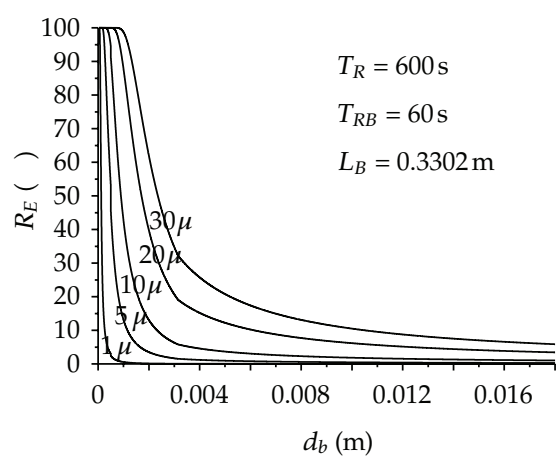

(c)

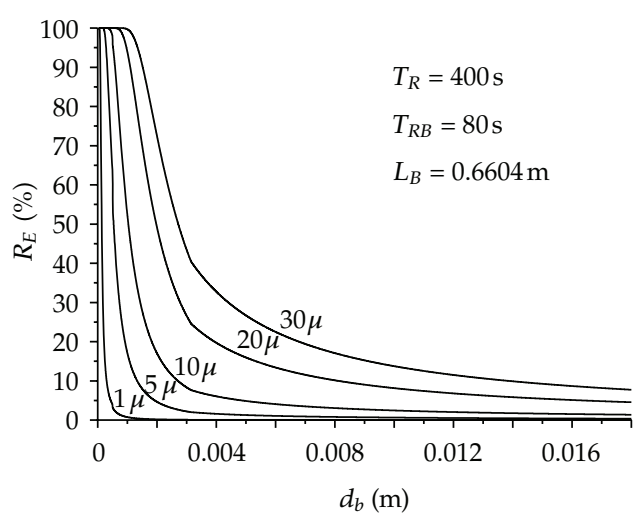

(b)

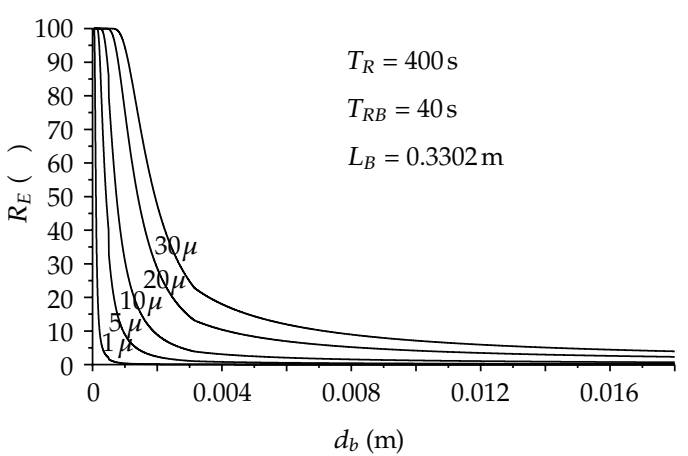

(d)

Figure 5: Prediction of the inclusion removal rate in a continuous casting tundish, (a) Constant $T_{R}$ and $L_{B}$, (b) Decrease of $T_{R}$ in $200 \mathrm{~s}$, (c) Decrease of $L_{B}$ by half, and (d) Decrease of $T_{R}$ and decrease of $L_{B}$ by half.

$50 \%$ causing a drop of $52 \%$ on $R_{E}$. Finally, the two previous reductions were put together, Figure $5(\mathrm{~d})$, and resulted in a $T_{R B}$ decrease of $66 \%$ inducing an $R_{E}$ value of $6 \%$. According to these results, $R_{E}$ is a direct function of $T_{R B}$. As in the majority of the tundish systems $L_{B}, T_{R}$, and $T_{R B}$ are constants, $R_{E}$ depends exclusively on the bubble attachment mechanism which is a very inefficient process as has been shown above. However, to explain the benefices reported from other modelling studies $[8,9,26]$ and those observed in practice $[8,28]$, where the argon bubbling helps a lot the inclusion removal, it is necessary to consider additionally the fluidynamics analysis of the system. This need is focused in the strong modification of the flow patterns produced by the argon bubbling; first of all, the bubble curtain redirects the flow towards the free surface, and secondly, the leaving flow from the curtain shows a plug behavior promoting a bigger inclusion uncoupling. As a consequence of these patterns, it is possible to obtain a considerable improvement on the inclusion removal.

\subsection{Mathematical Analysis}

In order to confirm the last hypothesis, a mathematical simulation of the fluidynamics in a tundish equipped with a turbulence inhibitor and under argon bubbling was carried out, in which $R_{E}$ was only calculated by fluidynamics effects (Stoke's flotation). Since there are many 


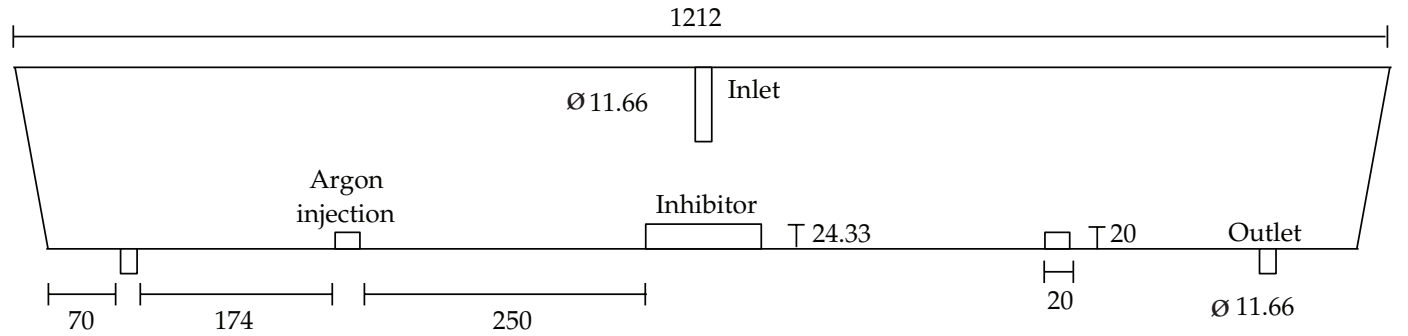

(a)

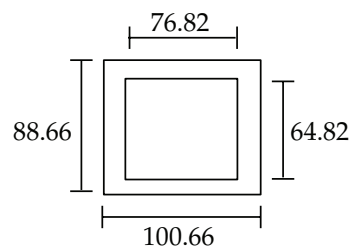

(b)

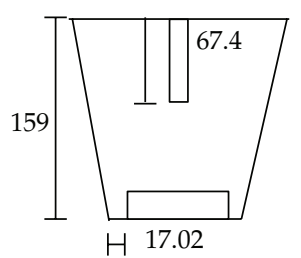

(c)

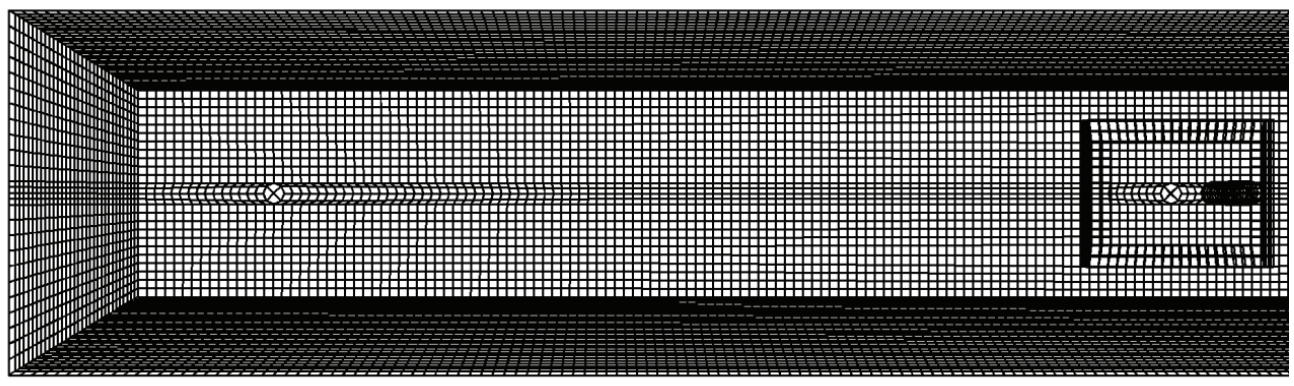

(d)

Figure 6: Characteristic dimensions of the continuous casting tundish (a) Frontal view, (b) Turbulence Inhibitor (TI) upper view, (c) Lateral view, and (d) Computational grid.

different tundish configurations, it was considered a typical slab tundish configuration and the numerical assumptions employed in a previous published work [9]. The characteristic dimensions of the tundish and the mesh used in this study are presented in Figure 6.

It should be taken into account that the inclusions are only removed when they reach the free surface; consequently, when the movement of the steel towards the free surface is acquired, a better removal percentage can be expected. It is important to notice that $R_{E}$ could be anticipated to be bigger than the one calculated by attachment since the area of removal is also bigger; due to the difference of densities the uncoupling mechanism is easier than the bubble attachment mechanism.

Observing the flow pattern changes in Figures 7 and 8, it can be seen that when argon is not injected, the fluid flow is directed by the turbulence inhibitor towards the free surface inducing a better removal efficiency since it promotes a redirection of the inclusion to the steel-slag interface. However, nearly at half of the distance between the inlet and the outlet, the steel moves downwards; this change has as a consequence that the inclusions move far from the interface, because of that, most of the inclusions are removed mainly at the first half of the tundish. Nevertheless, when the argon is injected, the flow patterns have 


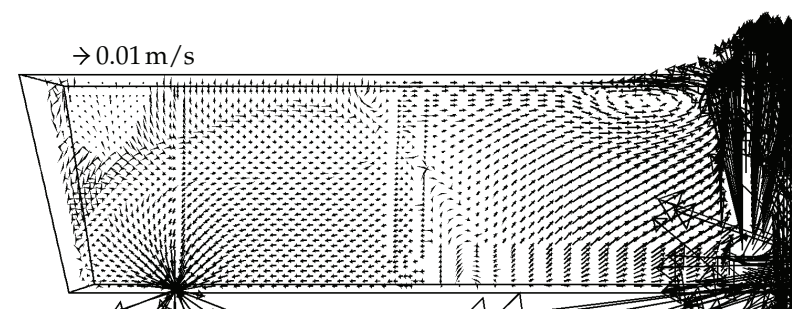

(a)

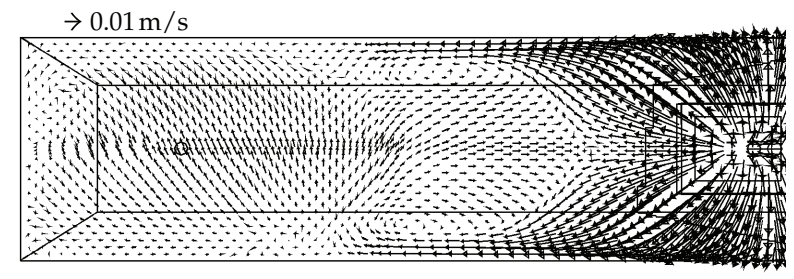

(b)

Figure 7: Velocity profiles inside the tundish without argon injection, (a) At the symmetric-longitudinal plane and (b) At the tundish steel level.

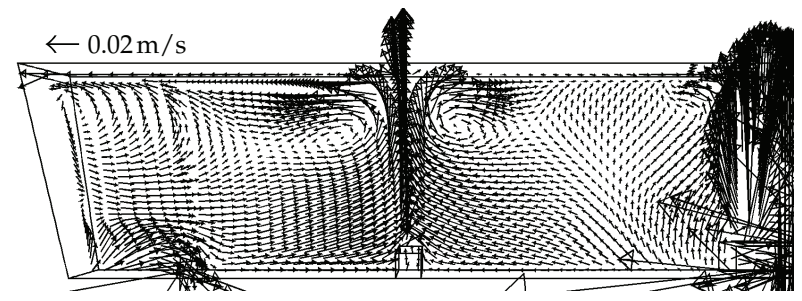

(a)

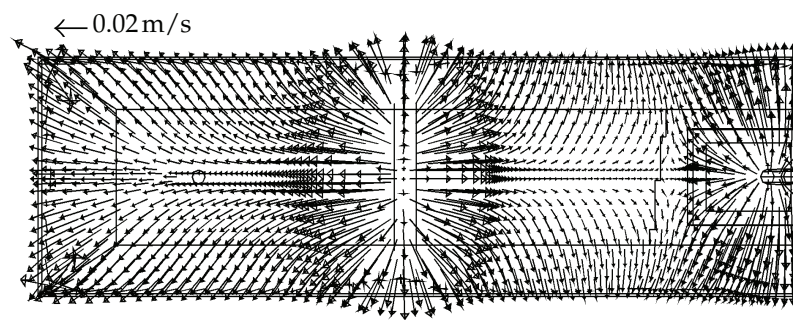

(b)

Figure 8: Velocity profiles inside the tundish with argon injection, (a) At the symmetric-longitudinal plane and (b) At the tundish steel level.

a strong change since two recirculation patterns are produced before and after the argon bubbling zone. These two changes generate a major removal percentage of inclusion due to the recirculation patterns.

For this study, the alumina inclusions were fed in the tundish entry nozzle and it was considered that the removed inclusions were only those that reach the tundish steel-slag interface. Since the most difficult inclusion removal size are those smaller than 30 microns, the results for that range are shown in Figure 9, where it can be observed that without argon, 


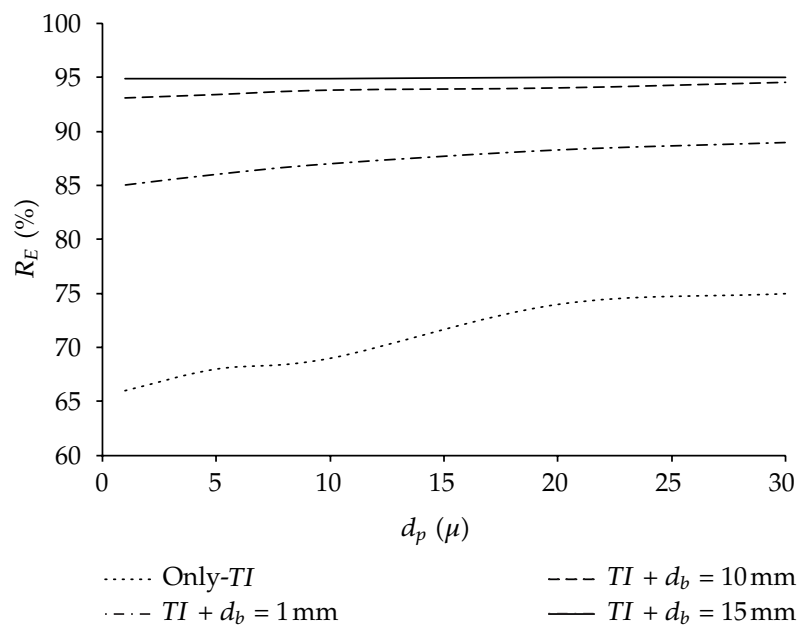

Figure 9: Non metallic Inclusion removal rate considering only the fluidynamics effect.

bubbling $R_{E}$ is near to $70 \%$ only by fluid flow. Now, if it is considered argon injection with $d_{b}=1 \mathrm{~mm}, R_{E}$ is improved by a further $15 \%$ just for fluidynamics, even more, if we add the theoretical $R_{E}$ by bubble attachment (Figure 5(a)) the total $R_{E}$ should be close to $100 \%$. Nevertheless, for more regular bubble diameters such as $d_{b}=10 \mathrm{~mm}$ or bigger like $15 \mathrm{~mm}$, the bubble curtain effects on steel movement is larger inducing a major displacement of the fluid to the interface steel-slag; consequently, $R_{E}$ must increase as actually is happening since $R_{E}$ achieves values close to $90 \%$. Thus, even $R_{E}$ by bubble attachment is quite low (near to $21 \%$ ), the total $R_{E}$ should be bigger than $90 \%$. It is important to notice that the total $R_{E}$ is not only a direct sum of both percentages. Figure 10 shows the combination of the two mechanisms and shows the increasing of the total $R_{E}$.

With these results it can be concluded that the inclusion removal rate in the tundish is efficient, employing argon bubbling mainly by the fluid flow pattern changes rather than by bubble attachment. Additionally, it can be established that it is imperative to consider the summation of both removal mechanisms to compute a better approximation of this important operation.

Finally, it is important to mention that these higher values of $R_{E}$ are a close approximation, since many of the inclusions that reach the interface never get absorbed by the slag and some others get back to the steel flow again, due to the strong turbulence of the liquid steel; consequently, this removal percentage is a powerful indicative of the way a tundish reactor is working on the inclusion removal, but until now it still impossible to establish that these results are definitive.

\section{Conclusions}

The non metallic inclusion removal mechanism by argon bubbling effects in a continuous casting tundish operation is analyzed analytically and by mathematical simulation involving a great number of variables. After analyzing the alumina inclusion removal rate by bubble attachment and by bubble fluidynamics effects the following conclusions can be drawn. 


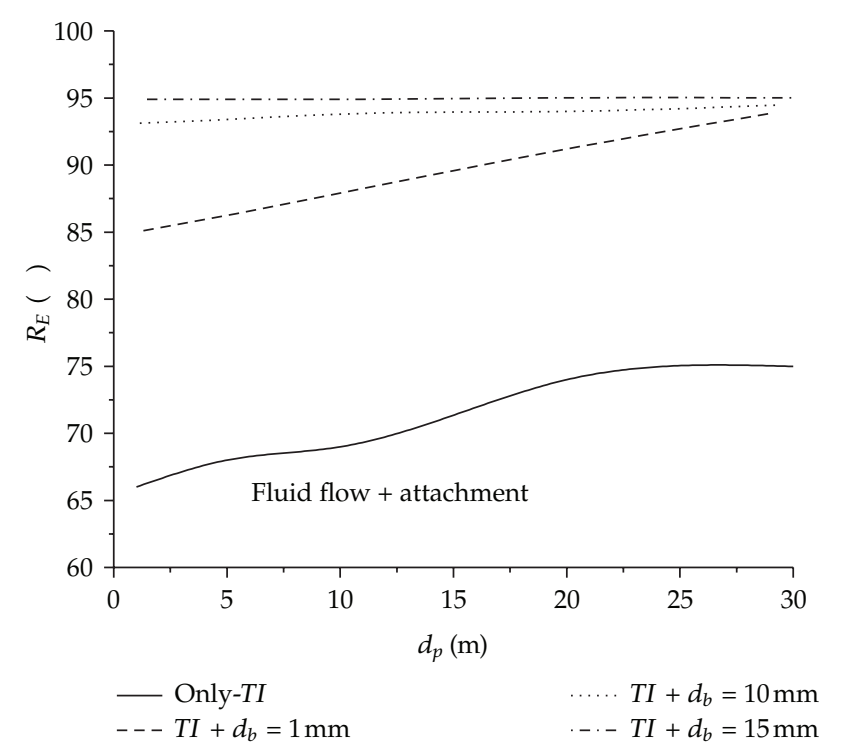

Figure 10: Non metallic Inclusion removal rate considering the sum of the fluidynamics effect and the bubble attachment.

(1) The results show that the film rupture between the inclusion and the bubble is easier by the formation of a hole and this mechanism has a dependency of the inclusion type.

(2) Since the current results show bigger $t_{i}$ values, this work demonstrates that the model used to calculate $t_{i}$ is important and as a consequence smaller attachment limits are obtained. At the same time, these increased values of $t_{i}$ turn out in smaller percentage of the alumina inclusion collection probability.

(3) The removal rate $\left(R_{E}\right)$ shows more dependency on other variables such as $T_{R}$ and $L_{B}$; those variables show an indirect effect on $R_{E}$ since it affects directly $T_{R B}$, which represents the controlling variable on the inclusion removal by bubble attachment.

(4) The results indicate that it is required to have very small bubble diameters to achieve acceptable $R_{E}$ percentages, however, in the real process, this consideration is almost impossible to get, and the real bubble diameters are around $10 \mathrm{~mm}$ resulting in a very inefficient inclusion removal process in the tundish by bubble attachment.

(5) Despite of conclusion four, the inclusion removal rate in the tundish is efficient employing argon bubbling, mainly by the fluid flow patterns changes rather than by bubble attachment. Then, it can be established that is imperative to consider the summation of both removal mechanisms, to compute a better approximation of this important operation. 


\section{Nomenclature}

A : Dimensionless parameters which are functions of the Reynolds bubble

$B$ : $\quad$ Dimensionless parameters which are functions of the Reynolds bubble

C: $\quad$ Dimensionless parameters which are functions of the Reynolds bubble

$D$ : Dimensionless parameters which are functions of the Reynolds bubble

$d_{p}: \quad$ Particle diameter

$d_{b}$ : $\quad$ Bubble diameter

$d_{0}$ : Porous diameter

g: $\quad$ Gravity

$h_{\text {crit: }}$ Critical film thickness

$k$ : $\quad$ Shape factor $=4$

$n_{o}: \quad$ Initial inclusion concentration

$n$ : $\quad$ Inclusion concentration

$N_{\mathrm{Re}, \mathrm{O}}$ : Reynolds bubble

$P: \quad$ Collection probability

$P_{\text {att }}: \quad$ Attachment probability

$P_{c}: \quad$ Collision probability

$P_{\text {det }}:$ Detachment probability

$Q_{g}: \quad$ Gas flow rate

$R_{E}$ : Inclusion removal rate

$t_{i}:$ Induction time

$t_{c}: \quad$ Collision time

$t_{\text {fr }}$ : Drainage time

$t_{s}: \quad$ Sliding time

$t_{\mathrm{fc}}$ : Film drainage and rupture time during collision

$T_{F}$ : Steel temperature $(1800 \mathrm{~K})$

$T_{0}$ : $\quad$ Gas temperature $(300 \mathrm{~K})$

$u_{p}$ : Particle velocity

$u_{B}$ : Bubble velocity.

Greek symbols

$\rho_{p}:$ Particle density

$\rho_{g}$ : Gas density

$\sigma_{L}:$ Superficial tension

$\mu_{L}$ : Liquid viscosity

$\theta$ : Polar angle

$\theta_{c}$ : Polar angle at the end of the interaction slidingcontact

$\theta_{0}$ : Polar angle at the beginning of the interaction slidingcontact

$\tau$ : Resident time of the steel in the bubble region in the tundish

$\varepsilon$ : The inclusion removal efficiency.

\section{Acknowledgments}

The authors give thanks to the following institutions: DGEST, ITM, PROMEP, and SNI for their permanent support to the Academic Research Group on Mathematical Simulation of Materials Processing and Fluid Dynamics. 


\section{References}

[1] Y. Sahai and T. Emi, "Melt flow characterization in continuous casting tundishes," ISIJ International, vol. 36, no. 6, pp. 667-672, 1996.

[2] L. Zhang, S. Taniguchi, and K. Cai, "Fluid flow and inclusion removal in continuous casting tundish," Metallurgical and Materials Transactions B, vol. 31, no. 2, pp. 253-266, 2000.

[3] C. M. Fan, R. J. Shie, and W. S. Hwang, "Studies by mathematical and physical modelling of fluid flow and inclusion removal phenomena in slab tundish for casting stainless steel using various flow control device designs," Ironmaking and Steelmaking, vol. 30, no. 5, pp. 341-347, 2003.

[4] L. Zhang and S. Taniguchi, "Fundamentals of inclusion removal from liquid steel by attachment to rising bubbles," ISS Transactions, vol. 28, no. 9, pp. 55-79, 2001.

[5] S. Garcia-Hernandez, J. J. de Barreto, J. A. Ramos-Banderas, and G. Solorio-Diaz, "Modeling study of the vortex and short circuit flow effect on inclusion removal in a slab tundish," Steel Research International, vol. 81, no. 36, pp. 453-460, 2010.

[6] J. Strandh, K. Nakajima, R. Eriksson, and P. Jonsson, "A mathematical model to study liquid inclusion behavior at the steel-slag interface," ISIJ International, vol. 45, no. 12, pp. 1838-1847, 2005.

[7] M. Valdez, G. S. Shannon, and S. Sridhar, "The ability of slags to absorb solid oxide inclusions," ISIJ International, vol. 46, no. 3, pp. 450-457, 2006.

[8] Q. Hou, Q. Yue, H. Wang, Z. Zou, and A. Yu, "Modelling of inclusion motion and flow patterns in swirling flow tundishes with symmetrical and asymmetrical structures," ISIJ International, vol. 48, no. 6, pp. 787-792, 2008.

[9] A. Ramos-Banderas, R. D. Morales, J. D. J. Barreto, and G. Solorio-Diaz, "Modelling study of inclusions removal by bubble flotation in the tundish," Steel Research International, vol. 77, no. 5, pp. 325-335, 2006.

[10] L. T. Wang, Q. Y. Zhang, S. H. Peng, and Z. B. Li, "Mathematical model for growth and removal of inclusion in a multi-tuyere ladle during gas-stirring," ISIJ International, vol. 31, no. 3, pp. 331-337, 2005.

[11] L. T. Wang, Q. Y. Zhang, S. H. Peng, and Z. B. Li, "Mathematical model for removal of inclusion in molten steel by injecting gas at ladle shroud," ISIJ International, vol. 45, no. 8, pp. 1138-1144, 2005.

[12] L. Zhang, S. Taniguchi, and K. Matsumoto, "Water model study on inclusion removal from liquid steel by bubble flotation under turbulent conditions," Ironmaking and Steelmaking, vol. 29, no. 5, pp. 326-336, 2002.

[13] L. Zhang and S. Taniguchi, "Fundamentals of inclusion removal from liquid steel by bubble flotation," International Materials Reviews, vol. 45, no. 2, pp. 59-82, 2000.

[14] L. Wang, H. G. Lee, and P. Hayes, "Prediction of the optimum bubble size for inclusion removal from molten steel by flotation," ISIJ International, vol. 36, no. 1, pp. 7-16, 1996.

[15] M. Iguchi, H. Kawabata, Y. Ito, K. Nakajima, and Z. I. Morita, "Continuous measurements of bubble characteristics in a molten iron bath with Ar gas injection," ISIJ International, vol. 34, no. 12, pp. $980-$ 985, 1994.

[16] G. S. Dobby and J. A. Finch, "Particle size dependence in flotation derived from a fundamental model of the capture process," International Journal of Mineral Processing, vol. 21, no. 3-4, pp. 241-260, 1987.

[17] A. V. Nguyen and S. Kmet, "Probability of collision between particles and bubbles in flotation: the theoretical inertialess model involving a swarm of bubbles in pulp phase," International Journal of Mineral Processing, vol. 40, no. 3-4, pp. 155-169, 1994.

[18] A. V. Nguyen, J. Ralston, and H. J. Schulze, “On modelling of bubble-particle attachment probability in flotation," International Journal of Mineral Processing, vol. 53, no. 4, pp. 225-249, 1998.

[19] H. J. Schulze, "Hydrodynamics of bubble-mineral particle collisions," Mineral Processing and Extractive Metallurgy Review, vol. 5, pp. 43-67, 1989.

[20] J. P. Rogler, L. J. Heaslip, and M. Mehrvar, "Inclusion removal in a tundish by gas bubbling," Canadian Metallurgical Quarterly, vol. 43, no. 3, pp. 407-416, 2004.

[21] H. Arai, K. Matsumoto, S. I. Shimasaki, and S. Taniguchi, "Model experiment on inclusion removal by bubble flotation accompanied by particle coagulation in turbulent flow," ISIJ International, vol. 49, no. 7, pp. 965-974, 2009.

[22] A. Vargas-Zamora, R. D. Morales, M. Diaz-Cruz, J. Palafox-Ramos, and J. D. J. Barreto-Sandoval, "Inertial and buoyancy driven water flows under gas bubbling and thermal stratification conditions in a tundish model," Metallurgical and Materials Transactions B, vol. 35, no. 2, pp. 247-257, 2004. 
[23] A. Ramos-Banderas, R. D. Morales, L. García-Demedices, and M. Díaz-Cruz, "Mathematical simulation and modeling of steel flow with gas bubbling in trough type tundishes," ISIJ International, vol. 43, no. 5, pp. 653-662, 2003.

[24] L. C. Zhong, L. Y. Li, B. Wang, L. Zhang, L. X. Zhu, and Q. F. Zhang, "Fluid flow behaviour in slab continuous casting tundish with different configurations of gas bubbling curtain," Ironmaking and Steelmaking, vol. 35, no. 6, pp. 436-440, 2008.

[25] D. S. Kumar, T. Rajendra, R. Prasad, A. Sarkar, and M. Ranjan, "Forced flotation of inclusions in tundish," Ironmaking and Steelmaking, vol. 36, no. 6, pp. 470-475, 2009.

[26] A. Cwudzinski, "Numerical simulation of liquid steel flow and behaviour of non-metallic inclusions in one-strand slab tundish with subflux turbulence controller and gas permeable barrier," Ironmaking and Steelmaking, vol. 37, no. 3, pp. 169-180, 2010.

[27] K. Chattopadhyay, M. Hasan, M. Isac, and R. I. L. Guthrie, "Physical and mathematical modeling of inert gas-shrouded ladle nozzles and their role on slag behavior and fluid flow patterns in a deltashaped, four-strand tundish," Metallurgical and Materials Transactions B, vol. 41, no. 1, pp. 225-233, 2010.

[28] C. Marique, A. Dong, and J. P. Mahieu, "Bubbling of inert gas into the tundish. A means to improve steel cleanliness," Iron and Steelmaker, vol. 17, no. 9, p. 15, 1990. 


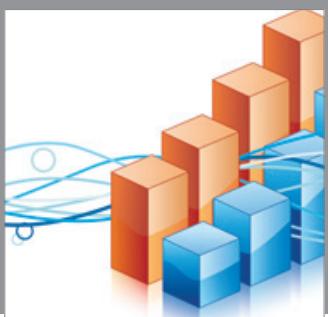

Advances in

Operations Research

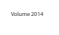

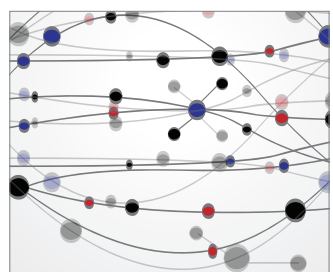

\section{The Scientific} World Journal
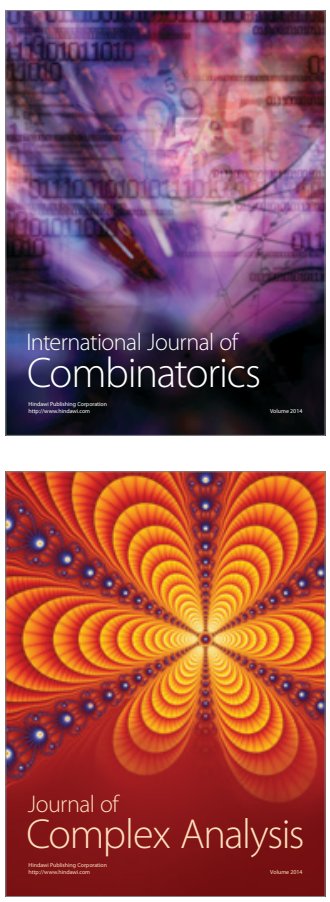

International Journal of

Mathematics and

Mathematical

Sciences
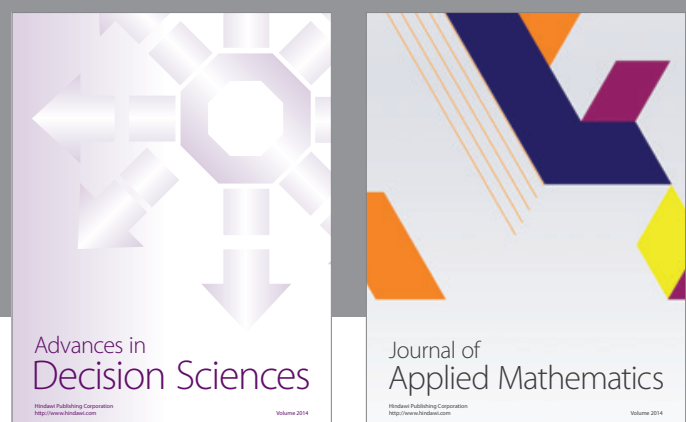

Journal of

Applied Mathematics
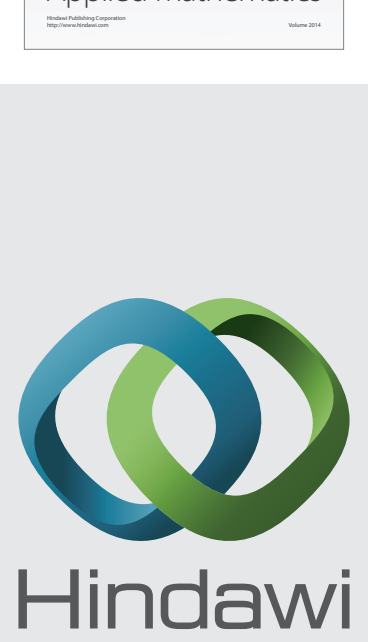

Submit your manuscripts at http://www.hindawi.com
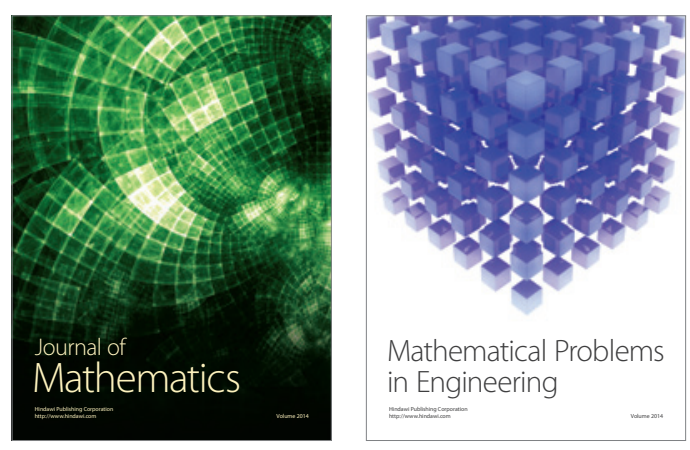

Mathematical Problems in Engineering
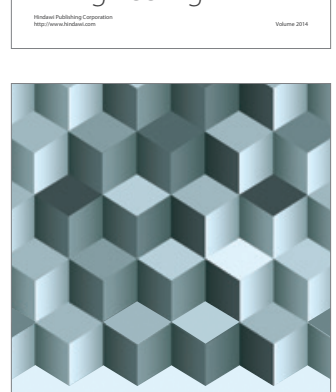

Journal of

Function Spaces
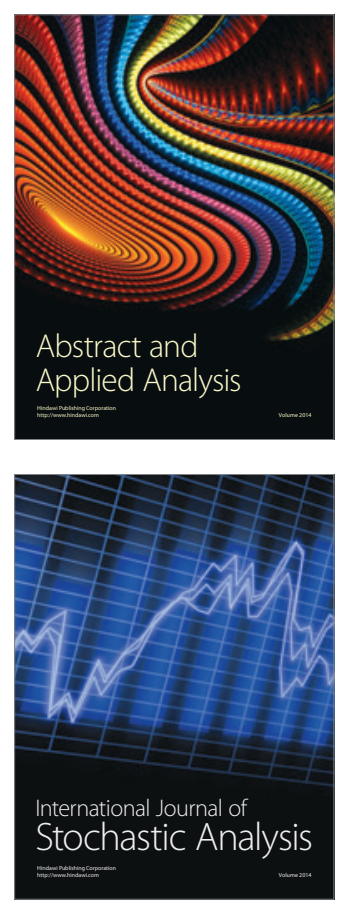

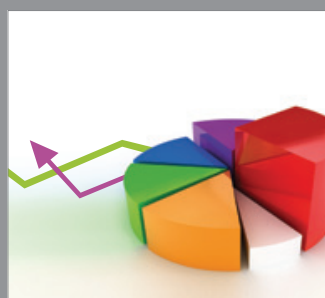

ournal of

Probability and Statistics

Promensencen
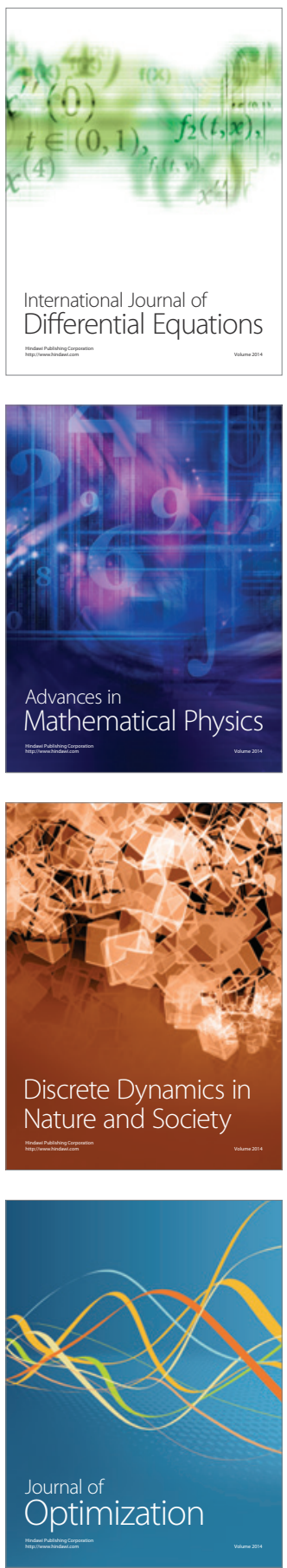